\title{
A IGNORÂNCIA HISTÓRICA DOS DIREITOS HUMANOS NO BRASIL
}

\author{
Bárbara Canto ${ }^{30}$ \\ Camila Sant'Ana Vieira Ferraz Milek ${ }^{31}$
}

\section{Resumo}

O presente artigo visa abordar a difícil adesão e efetividade dos direitos humanos no Brasil a partir da perspectiva da filosofia e da sociologia. Tanto na organização do espaço público, como no meio institucional e no imaginário do cidadão brasileiro, os direitos humanos encontram entraves que dificultam sua concretude. Tais entraves partem da organização social e como ela tem ocorrido historicamente.

Palavras-chave: direitos, humanos, história, sociedade.

\section{THE HISTORICAL IGNORANCE OF HUMAN RIGHTS IN BRAZIL}

\begin{abstract}
This article intends approach the hard jointed and effectivity of human rights in Brazil under the perspectivity of philosophy and sociology. Both in the layout of public space, the institutional sphere and the imaginary of the Brazilian citizen, the human rights find hindrances that difficult your establishment. Such hindrances arise from social environment and how it occurred historically.
\end{abstract}

Key-words: rights, humans, history, society.

\section{Introdução}

A Declaração Universal dos Direitos Humanos, de 1948 salienta que todos os seres humanos nascem iguais e livres, merecendo assim tratamento digno e a garantia de direitos. A Constituição Federal Brasileira de 1988 e vigente até então contempla o conteúdo da Declaração Universal, por exemplo, no Artigo $5^{\circ}$ :"Todos são iguais perante a lei, sem distinção de qualquer natureza, garantindo-se aos brasileiros e aos estrangeiros residentes no País a inviolabilidade do direito à vida, à liberdade, à igualdade, à segurança e à propriedade.” (Constituição, 1988). Daí se seguem 126 cláusulas (ou parágrafos) que versam

\footnotetext{
${ }^{30}$ Mestra em Filosofia pela UFPR e membro do Grupo de Estudos de Política Brasileira Contemporânea (GEsPBC). E-mail: barbaracanto8@gmail.com

${ }^{31}$ É professora de Filosofia pela Secretaria de Estado de Educação do Paraná, doutoranda em Filosofia pela UFPR e membro do Grupo de Estudos de Política Brasileira Contemporânea (GEsPBC). E-mail: csvferraz@hotmail.com
} 
sobre as liberdades fundamentais, como a de expressão, do âmbito privado, de crença e das restrições à violência, abuso ou difamação, por exemplo. Basicamente, os que lutam pelos direitos humanos visam garantir esses direitos fundamentais.

\section{Humanos e sub-humanos}

Nossa explanação se inicia levantando algumas questões que amparadas em pensadores brasileiros principalmente, mas com uma pequena ajuda de europeus também, que possuindo uma preocupação sobre os fenômenos sociais, suas causas e origem se debruçaram sobre eles. Assim, amparadas nestas pesquisas desenvolvemos uma reflexão sobre o papel dos direitos humanos no Brasil, sua importância e os desafios que possui para se consolidar como de fato seu nome já o define: como Direito.

Para considerar a validade destes direitos, dois elementos devem ser considerados direitos inalienáveis para qualquer ser humano: a igualdade e a liberdade. Teoricamente, o que pode tornar esse entendimento complexo é o que é a igualdade e o que é a liberdade civil e quais seriam seus limites. A igualdade é considerada necessária para que os sujeitos de uma sociedade possam ter liberdades garantidas e possibilidades de sanar suas necessidades mais básicas como moradia, alimentação, saúde e educação sem submeter-se a outros. Aqui no Brasil, ainda temos mais fatores que complexificam a questão: a grande desigualdade social e uma recente onda que tem despertado valores da época da ditadura, que desconsideram a igualdade como direito inalienável. Um terceiro fator, talvez mais elementar que os anteriores e mais profundo é: O que é o ser humano? Como posso definir o ser humano e, se posso, que direitos são cabíveis a ele? É esse o ponto que está por trás das discordâncias sobre os limites dos direitos humanos.

Por isso, gostaríamos de analisar duas das frases ditas em oposição aos direitos humanos e investigar que noção de ser humano ou que noção de direito está ali subentendida. A primeira, dita coloquialmente em diversos ambientes e costumeiramente utilizada para argumentar contra os que defendem os direitos humano é: direitos humanos para humanos direitos. Essa frase nega a primeira frase do Artigo $5^{\circ}$ : todos são iguais perante a lei. A proposta da frase que parece um mero jogo de palavras é a de que apenas os humanos considerados direitos - o que deve estar próximo do "cidadão de bem" - possam ter acesso aos direitos humanos. Ou seja, os que não se encaixam nesse perfil seriam considerados subhumanos, perdendo o direto à liberdade, à segurança e à propriedade.

Saindo um pouco do cenário nacional e pensando na história mundial, este tipo de pensamento pode ser associado ao que anteriormente baseou várias práticas higienistas cruéis 
na história, que se baseavam em uma noção de ser humano muito mais restrita do que temos hoje, como por exemplo, o holocausto nazista, onde judeus e demais povos não arianos eram considerados inferiores, o que justificou o assassinato massivo dos mesmos; a escravidão, que a partir de uma pseudociência biologicista inferiorizava os negros a ponto de que, já que não eram humanos, poderiam ser utilizados como objetos de trabalho ou lazer; a falta de direitos para as mulheres, que ao considerar características naturais que impediriam que uma mulher fosse apta a determinadas funções na sociedade, restringindo-a à submissão ao pai ou ao marido e às funções domésticas; e, por fim, a violenta prática manicomial que se inicia no século XIX e tem como resultado, por exemplo, o chamado holocausto brasileiro, onde mais de 60.000 internos, considerados humanos inferiores cognitivamente foram mortos em experiências ou pelas baixas condições de vida no internamento tendo seus corpos comercializados, localizado em Barbacena, Minas Gerais ${ }^{32}$. Em todos estes casos, as vítimas de encarceramento, trabalho forçado ou assassinato não foram consideradas humanos direitos, seja por sua condição física - diferente cor de pele, traços, cognição, etc. seja por sua condição moral - diferentes tradições, cultura de um povo, ou até mesmo a não inserção em valores de determinada sociedade, sempre condicionados a causas físicas. Retirando seu lugar de pertencimento na humanidade, justificavam-se práticas discriminatórias das mais cruéis. Os direitos humanos foram criados justamente no período pós-guerra, para evitar que isso voltasse a acontecer e que houvesse um tratamento humano inclusive para os acusados de participação.

Após esses exemplos execráveis que quase ninguém defenderia em público sem sentir vergonha, como é que podemos ouvir a mesma argumentação ser utilizada ainda hoje? Por causa de uma noção de ser humano que - apesar de já ser muito mais inclusiva do que as mencionadas anteriormente - ainda possui os resquícios do passado e não compreende todo ser humano como um verdadeiro ser humano.

\section{0 brasileiro}

Podemos ainda aproximar nosso olhar do cenário nacional, e nos perguntarmos como tal discurso pode ocorrer em um país como o nosso. Jessé Souza, em A Tolice da Inteligência Brasileira pode nos ajudar a compreender que forma esta divisão entre humanos e subhumanos toma em nosso país ${ }^{33}$. A pergunta sobre o que é o ser humano será acompanhada por

\footnotetext{
${ }^{32}$ ARBEX, Daniela. Holocausto Brasileiro - vida, genocídio e 60 mil mortes no maior hospício do Brasil, geração, 2013, Brasil.

33 É preciso ressaltar que Jessé vai mais além e retrata a relação do brasileiro com o estado e a economia e
} 
outra: o que é o brasileiro? Dela, retiram-se conclusões que podem esclarecer os motivos da recusa aos direitos humanos:

Por que existiria o interesse em esconder, distorcer ou, como dizemos na vida cotidiana, o interesse em "mentir" sobre como o mundo social realmente é? Ora, como diria o insuspeito Max Weber, os ricos e felizes, em todas as épocas e em todos os lugares, não querem apenas ser ricos e felizes. Querem saber que têm "direito" à riqueza e felicidade. Isso significa que o privilégio -mesmo o flagrantemente injusto, como o que se transmite por herança - necessita ser "legitimado", ou seja, aceito mesmo por aqueles que foram excluídos de todos os privilégios. (Jessé Souza, Tolice da Inteligência Brasileira, 2015, Leya. Prefácio, pág. 9)

Para que se justifiquem os privilégios de alguns, não se pode considerar que todos são iguais. O patamar social em que eles se encontram não é mais justificado, torna-se injusto. É preciso que essa superioridade seja justificada, mas como? A partir do momento em que me torno superior ao outro, meu privilégio se torna direito a partir da minha conduta. $\mathrm{O}$ que ocorre é que no Brasil, segundo Jessé, inclusive teóricos renomados contribuem para esse quadro.

Jessé nos mostra como o que entendemos por brasileiro parte de uma grande máquina de sustentação de privilégios da elite que trabalha em diversos âmbitos, inclusive na ciência social. Mas de onde esse discurso hoje tão firme e compartilhado se origina? Data do início da investigação sobre a construção do Brasil, onde o país se instaurou sustentado pelo genocídio indígena e pela escravidão.

O racismo científico - que fomentou várias das práticas violentas acima colocadas -, com maior força em torno de 1920, justificava uma hierarquização entre raças a partir da diferença genética que existiria entre elas. O que impede qualquer alteração na ordem hierárquica, ou seja, o que é inferior será sempre inferior - física e moralmente.

Outros discursos, mais bem adaptados as novas realidades começam a surgir. Pesquisadores que, realmente preocupados em uma investigação sobre o povo brasileiro procuram em suas origens como definir o brasileiro. Abandona-se uma caracterização dos indivíduos que seria de base hierárquica, não mais caracteriza-os biologicamente e se assume uma caracterização pelos valores e hábitos de um povo - o culturalismo. Nesse novo panorama, as sociedades se diferenciam por seu estoque cultural. Porém, a definição dessa cultura pode tornar-se um mito, uma falsa definição de cultura que em nada supera o racismo

como isto está enraizado a nossa história e permanece inclusive na ciência social. Ele chega a tratar das manifestações de 2013, etc. Aqui, nos deteremos nas considerações sobre quem é o brasileiro - o ser humano de nossa experiência. 
científico de outros tempos. Isso corre quando uma cultura é considerada por características inalteradas desde seu início e arraigada a preconceitos mais antigos ainda do que elas, e ainda mais, passa a ser usada para a comparação entre culturas, a fim de classificar algumas como mais avançadas e outras mais atrasadas. É o culturalismo racista, que forja um mito fundador que é usado para nos significar cotidianamente ${ }^{34}$. Vejamos que elementos estariam por trás da forma como o brasileiro julga ser.

O primeiro é um dos pilares do pensamento ocidental: a dicotomia entre corpo e razão, onde, segundo Platão, a razão seria superior e única com o acesso à verdade, enquanto o corpo estaria limitado pelo mundo físico, sendo inferior ${ }^{35}$. O segundo, seria uma leitura unilateral das teses de Max Weber por parte dos sociólogos brasileiros, que coloca uma caracterização do protestantismo ascético - como figura de uma personalidade ativa, dotado de vontade, disciplina e autocontrole - como nos Estados Unidos ${ }^{36}$. Tais elementos são complementares, na medida em que a análise de Weber já se encontra, como o pensamento ocidental em geral, tomado pelo postulado que separa o sensível e o inteligível, de forma que as características que teriam levado ao desenvolvimento econômico partem todas do raciocínio em detrimento da sensibilidade ou afetividade. Em contrapartida, o brasileiro teria características muito particulares.

Com essas duas linhas de pensamento, em 1933 Gilberto Freire publica Casa Grande e Senzala, uma renomada obra que constitui os currículos de cursos universitários e do ensino básico. Nessa obra surge a criação da identidade nacional com um valor positivo para a ligação afetiva do brasileiro e suas características passionais, relacionadas à miscigenação, que foi utilizada para a unificação da nação pelo governo de Getúlio Vargas. O brasileiro, seria um ser de fácil sociabilidade, que toma as decisões de forma a favorecer seus próximos, não racionalmente, mas afetivamente. Aqui, já está presente o primeiro elemento colocado, o de que existe uma separação entre a afetividade - que pertence ao corpo - e a racionalidade que seria característica dos povos desenvolvidos -, por exemplo na figura do protestante ascético salientado por Weber. Ela também separa seres humanos por características que, mesmo que não sejam oriundas da genética, são tão naturalizadas quanto. É um ponto

\footnotetext{
${ }^{34}$ SOUZA, 2015, p. 321.

${ }^{35}$ Neste ponto, Jessé faz referência ao dualismo platônico, inscrito por exemplo em A República. Há uma hierarquização entre o inteligível e o sensível, onde o inteligível é o campo que possibilita o saber, enquanto o sensível leva ao engano. Tal teoria torna-se posteriormente um paradigma da filosofia ocidental e embasa uma concepção de mundo, sendo - de forma impensada - utilizada para julgar indivíduos e sociedades.

${ }^{36}$ Trata-se de uma leitura enviesada do pensamento de Weber feita pelos culturalistas. Enquanto Weber diagnostica a gênese do capitalismo, suas teorias serão utilizadas depois como justificativas moralizantes para a expansão do mesmo, além de serem utilizadas como parâmetro de comparação entre culturas (Jessé Souza, Tolice da Inteligência Brasileira, 2015, Leya, pág.89)
} 
nevrálgico da cultura brasileira que daria um significado uniforme e que perdura no tempo. A Afetividade, mesmo que seja parte da cultura brasileira, está presente nos primeiros habitantes do país e teria perdurado nos atuais, como herança. O intuito dessa caracterização era de dar uma significação positiva para o povo brasileiro e de criar uma caracterização unificada que enfrente tantas diversidades aqui presentes. Sua fácil sociabilidade com outros povos seria o que o torna único no globo.

Em seguida, na figura do homem cordial na obra Raízes do Brasil de Sérgio Buarque de 1936, inverte-se o valor e a alta afetividade e passionalidade do novo povo passam a ser as características que justificam nosso atraso em relação aos países desenvolvidos do globo. Mantém-se a dicotomia entre corpo e raciocínio, mas agora ela ganha um valor negativo. É isso que faz com que a personalização e o patrimonialismo imperem em nosso país. Seria uma corrupção inerente aos brasileiros que nos tornou, no passado, facilmente subjugados, e nos torna ainda hoje corruptos seja na esfera da vida privada, seja na esfera pública - mas nunca no mercado, que é entendido como neutro moralmente.

É preciso tratar dessa caracterização como um mito fundador, que retira a necessidade da busca pela verdade e que não teria sido investigado pelos pensadores que se seguiram na sociologia brasileira. Essas idealizações passam automaticamente, mesmo sendo hipóteses de um perfil genérico de uma nação com uma multiplicidade de seres, a ter valor de verdade. De fato, a definição de brasileiro como personalista e patrimonialista passa pelo decorrer da história dos estudos sociais brasileiros quase irretocável, e sem questionar o papel das grandes atrocidades que aqui ocorreram. A caracterização do que se dizia brasileiro em 1933 perdura, como se fosse uma cultura internalizada nos cidadãos atuais. Cria-se uma fronteira ontológica entre gente e sub-gente, ou seja, há uma diferença essencial entre os brasileiros e os demais. A caracterização cultural passa a ser entendida como essência daquele povo e perdura como uma herança maldita que justifica seu atraso ao invés de considerar as características de cunho histórico e social - a escravidão por exemplo, instituição que molda nosso país passa quase sem ser mencionada.

Apesar de manter a fixidez que aparecia no racismo científico, a ideia de estoque cultural parece mais maleável, de modo que um brasileiro possa colocar-se a partir de parâmetros fora de sua cultura, caso ele, individualmente consiga aumentar seu estoque cultural, ou imagine fazê-lo. Então o brasileiro se diferencia, colocando-se mais próximo do que caracteriza outros povos - por exemplo, ele é trabalhador, se esforça e pensa em ter um futuro melhor - enquanto pode criticar a figura genérica do brasileiro - os outros, que não conseguem superar as dificuldades é que são afetivos, personalistas e malandros. É a nova 
cara do racismo científico, mas não aumenta realmente as chances de desestagnar a hierarquia traçada outrora. Isto, pois o estoque cultural acumulado com o tempo não pode ser, de uma hora para outra, aumentado, mantendo assim uma distância instransponível entre as sociedades.

As ideias da ciência são repercutidas, bem ou mal, distorcidas ou não, através da mídia, universidades, tribunais e parlamentos. Assim se instaura o pensamento do status quo de forma tão firme. Naturaliza-se o discurso hegemônico. Além do mais, isso, que está presente nos mais renomados pensadores permeia o imaginário do brasileiro comum. $\mathrm{O}$ brasileiro em geral é considerado: amistoso, preguiçoso e malandro, ou seja: ele não é direito. O brasileiro que anuncia a frase, direitos humanos para humanos direitos, não se considera um brasileiro igual a estes demais, ele é um brasileiro que segue padrões globais de produção e de moral impecável, por isso, é o tipo de humano que merece sim, esses direitos. Há então uma fragmentação do que se entende por ser humano, que aqui se fragmenta na figura do brasileiro, e dos "brasileiros direitos", que teriam deixado pra trás essa quase natureza humana aqui criada. É por causa desse imaginário que se diz sem pudor esse tipo de frase, pois seria natural que nem todos os seres humanos são iguais - não por questões de contexto social mas por características intrínsecas a este ser humano.

Aí vamos a segunda frase: Bandido bom é bandido morto. O ser humano que foi considerado criminoso não teria direito sequer à vida, imagine só a um tratamento digno ou um julgamento justo. $\mathrm{O}$ que a frase esconde é $1^{\mathrm{o}}$ a crença na justiça brasileira; $2^{\circ}$ a impossibilidade da melhora do indivíduo considerado criminoso para que possa ser inserido novamente na sociedade. O bandido é intrinsecamente bandido, incapacitado de abandonar a cultura corrupta a qual pertence e não é dotado de nenhuma racionalidade. Por isso, a pessoa que diz essa frase não enxerga o sistema carcerário como uma possibilidade de aprendizado do presidiário, mas apenas como uma punição. Isto, pois o bandido é inerentemente, naturalmente um bandido, não pode por uma interferência externa deixar de sê-lo, ele nasce assim e morrerá assim. Além disso, a pessoa que fala tal frase pode também estar dizendo nas entrelinhas que, por determinado humano ser um bandido - não ser um humano direito - os humanos considerados direitos teriam o direito de utilizar a violência contra eles. Mas se o humano direito o fizer, não se torna bandido, pois age violentamente não com um ser humano, mas com um sub-humano. Nessa frase está incutida a mesma violência praticada outrora nos casos históricos que mencionamos.

O que se perde nessa argumentação? A consideração de toda a história, contexto social e cultural como formador do indivíduo. 
O homem cordial não tem classe social, mesmo em um país tão desigual como o Brasil sempre foi. Ou seja, desde o início essa noção esconde conflitos sociais de toda espécie e cria um ser "genérico" que existe unicamente para ser contraposto ao "protestante ascético" como símbolo da cultura norte-americana. Essa contraposição indica um caminho ao Brasil: o do afeto e da emotividade pré-moderna em direção ao mundo da racionalidade distanciada da impessoalidade protestante. (Jessé Souza, Tolice da Inteligência Brasileira, 2015, Leya, pág. 89)

Simplifica-se a análise da conjuntura atual e se retira toda a carga de desigualdade que se instaurou no Brasil desde os abusos cometidos contra índios e negros. Há de se restaurar esta história ${ }^{37}$ e além disso, integrar a análise do contexto social de nossa sociedade. Para isso, o sociólogo resgata o pensamento de Bourdieu.

\section{O capital simbólico}

O capital simbólico é determinante do acesso aos direitos em nossa sociedade, porém, existem outros fatores que devem ser considerados. Como a ascensão de parte da população a um nível econômico maior - a comentada ascensão da classe $\mathrm{C}$, por exemplo - de modo que a classe média teria aumentado em nosso país. Porém, existe um problema na divisão de classes brasileiras, pois elas normalmente consideram apenas o capital econômico, e não o capital cultural e o capital social. Apenas o capital econômico não pode unir pessoas em uma classe, pois por compartilharem os mesmos ganhos - a maiorias das definições de classe difundidas se fazem em torno ou dos salários ou de bens de consumo a longo prazo, como a casa, quantidade de banheiros, eletrônicos, etc. - as pessoas não compartilham dos mesmos ideais e nem dos mesmo hábitos na sociedade. Além disso, se se considera que no período de 2002 a 2012 houve uma ascensão da classe C, pode-se ter a impressão que as pessoas que passaram da classe baixa para a média ganham automaticamente os privilégios cristalizados daqueles que vêm de famílias que durante muito tempo já possuíam acesso ao capital simbólico. Aparentemente, o rápido aumento de rende seria suficiente para que a melhora de condição perdure e novamente, se culpa o indivíduo que permaneceu na classe baixa. Por exemplo, alguém, de uma família de classe média já de longa data tem acesso a um capital cultural que valoriza o estudo, a concentração, o autocontrole e a visão que aponta para o futuro - as características mencionadas por Weber. Alguém que recentemente ascendeu a chamada classe

\footnotetext{
${ }^{37}$ Após o lançamento de Tolice da inteligência brasileira, Jessé Souza lança a Elite do atraso, que investiga o peso da escravidão para os dias atuais no Brasil.
} 
média não tem o mesmo histórico de estudo, acesso a livros, hábitos que o favoreçam. Ela pode ter exemplo de cunho mais imediatista e de trabalhos braçais - lembrando da antiga divisão que data de Platão, onde o raciocínio é superior ao corpo, as atividades manuais são praticadas em sua maioria por pessoas menos favorecidas e não se tornam capital cultural, enquanto que o trabalho inventivo e intelectual é reservado a classes dominantes.

Então, o acesso ao capital cultural - que inclui capacidades que são exercitadas ao longo da vida, como concentração, bons métodos de estudos, plano de futuro, autocontrole, bem como o acesso a atividades intelectuais e artísticas, à boas escolas e universidades, à uma gama variada de formas de expressão cultural é o que pode diferenciar classes sociais no Brasil. A partir do acesso ao capital cultural, se consegue o capital social, que é o círculo de pessoas influentes ao seu redor que possibilitam o acesso a melhores vagas de emprego e oportunidades.

O capital cultural - tanto a produção quanto o acesso - parecem estar restritos à classe média e a elite. Pois, os conhecimentos valorizados culturalmente dependem de um setor de serviços que se concentra nas mãos de parte dessa classe média - advogados, arquitetos, publicitários, artistas, etc. Enquanto isso, a classe trabalhadora ainda tem que lidar coma ausência de tempo livre, por exemplo. Como se dedicar ao estudo detidamente se o tempo é tomado para a garantia das necessidades básicas? É o roubo do tempo das classes trabalhadoras que permite que as classes dominantes reservem aos seus filhos o tempo livre que fará com que desenvolvam bom capital cultural e social. Assim, se perpetua a distância entre eles e se aumenta a desigualdade.

A violência simbólica aparenta um caráter pacífico por não conter violência física, mas possui uma coerção não declarada e permanente. Ela estaria presente na ligação entre a mídia, política, jurisdição, universidades e os privilégios. Forma-se um discurso homogêneo e aparentemente inquestionável que visa fortalecer a manutenção dos privilégios da elite.

Se o privilégio tinha uma justificação nas tradições, atualmente, se inverte e assume aparentemente outra lógica: ele deve ser dado pelo esforço pessoal, mérito. O que o faz parecer não como um privilégio, mas como uma premiação. Caso não se consiga atingir determinados parâmetros - que são inspirados em um padrão externo, globalizado, ou a partir de uma classe superior -, o erro é apenas do indivíduo, que por suas características foi incapaz de sair de tal situação e por isso é culpado dela. Essa é uma das formas de violência simbólica. Além dessa, podemos ver o diferente acesso que determinadas classes têm a determinados lugares- shoppings, aeroportos, cinemas, bibliotecas, etc. Essa violência, apesar de não física, é muito grave. Isto, pois ela impede que o brasileiro possa deixar seu lugar, ou 
seja, impede sua liberdade de ir e vir e de ter acesso total ao que outras pessoas têm, apenas por serem quem são.

Dessa perspectiva, não são características inatas nem mesmo de uma cultura passada que data do início da formação do Brasil que molda o perfil dos brasileiros. Considerando-se o capital cultural, não é possível dividir essas classes entre dignos e indignos, como pode-se constatar da visão do culturalismo racista denunciado por Jessé. Ao contrário, ao considerarmos o capital cultural a história desses indivíduos e seu contexto social é levada à tona. Assim, se percebe como é falsa a divisão forçada que ainda hoje se faz entre humanos e sub-humanos, dignos e indignos. Percebe-se, que ser considerado um ser humano é uma construção social e não um dado natural ${ }^{38}$. E aí está a questão da igualdade em nossa constituição: ela é uma exigência ou um ideal a ser alcançado? Confunde-se as duas possibilidades e assim, parece válido classificarmos os que merecem mais direitos e os que merecem menos direitos.

É isso o que Jessé Souza quer extirpar ao sugerir uma diferente consideração do que é o brasileiro: A partir da inserção de Pierre Bourdieu na análise do que são os indivíduos em uma sociedade. $\mathrm{O}$ autor destaca a importância do capital econômico, mas principalmente o social e cultural na análise. Seriam os capitais cultural e social - mais do que o capital econômico - que têm diferenciado os brasileiros no decorrer dos anos. São os exemplos desde a infância que estão próximos do indivíduo, é o seu acesso a bens culturais como livros, peças de teatro, filmes e documentários, é o seu acesso aos lugares da cidade, o seu acesso a diferentes ideias que proporciona que o indivíduo se torne quem é e o que marca seu local na sociedade. $\mathrm{O}$ aumento de capital econômico traz consigo um aumento de capital cultural e social, mas demanda tempo para que as desigualdades cristalizadas historicamente sejam superadas.

Infelizmente, a limitação entre humanos e sub-humanos se dá e se vê de diversas formas em sociedade, seja historicamente ou geograficamente. Os espaços de uma cidade e a consideração de nossa história são meios de pulverizar a violência simbólica aqui mencionada. Essa violência simbólica permite que ainda sejam disseminados os preconceitos presentes no racismo e no culturalismo, para que se hierarquizem não só os indivíduos, mas as sociedades. Julgando os diferentes pelos mesmos parâmetros.

\footnotetext{
${ }^{38}$ SOUZA, 2015, pág. 357.
} 


\section{Tempo do mundo}

Nesta parte final do texto buscamos acompanhando toda a narrativa tida até aqui, contribuir com algumas questões que se desenvolveram em nossa história mais recente e que exemplifica o que estamos tratando. Falaremos sobre a falta de conhecimento de nossa própria história e como essa falta de conhecimento pode afetar muito fortemente a nossa visão sobre muitos dos problemas enfrentados pelos Direitos humanos em nosso país, assim como a falta deles pode acarretar em consequências muito graves para parte de nossa população que não tem seus direitos - estabelecidos lá na Carta Magna - atendidos.

Tempo do mundo, ou como relata em seu livro, O Novo Tempo do Mundo, o filósofo brasileiro Paulo Arantes, trata-se de um "clima internacional, suficientemente persuasivo para influenciar escolhas sociais e decisões políticas em arenas locais mais restritas" ${ }^{29}$. Dessa forma pode-se entender tempo do mundo como o contexto social e político que define determinada época histórica, englobando todo o mundo como dispondo do mesmo aparato político e social determinantes para fazer de uma sociedade aquilo o que ela é. Mais ainda, é a expressão que permite dizer que todas as partes do mundo compactuam do mesmo contexto social e político, e por isso, fazem parte da mesma conjuntura, da mesma ordem política e social.

Essa noção de tempo é muito prejudicial e inteiramente rechaçada por quem deseja fazer uma leitura mais crítica da história. A história é um processo político do qual não se pode simplesmente amontoar diversas culturas e tipos de sociedades num mesmo lugar, e simplesmente atribuir-lhes o mesmo status político-social sem levar em conta toda a sua história individual, tudo o que concorreu para dar-lhe as características que a tornaram exatamente o que é, fazer isso é correr o risco de apagar toda a herança cultural de um povo, limpá-lo de sua própria identidade.

Assim percebe-se como essa noção de um tempo mundial, "permitiu contornar o absurdo de comparar incomparáveis", ou seja, ela equiparava lugares que não tinham o mesmo processo cultural político-social, e os atribuía um lugar segundo sua posição na corrida desenvolvimentista, "tratava-se de aproximar ou afastar industrializações, revoluções, etc. enquanto processos ou acontecimentos histórico-mundial" ${ }^{40}$. Em outras palavras, ao tentar colocar sob o mesmo escrutínio diversas formas de organizações sociais aquelas que estivessem mais ou menos na mesma condição socioeconômica e política, estaria assim "dentro do tempo", seguindo este raciocínio, as outras que não acompanhassem o mesmo

\footnotetext{
${ }^{39}$ ARANTES, 2014, p. 27.

${ }^{40}$ ARANTES, 2014, p. 28.
} 
ritmo daquelas que ditavam a economia e as práticas sociais, estavam "atrasadas" em relação a elas, portanto, "fora do tempo". Este raciocínio permitiu, por exemplo, a divisão de regiões do globo baseando-se apenas na esfera econômica, em Primeiro, segundo e Terceiro mundo, ou para sermos mais atuais, em países desenvolvidos, emergentes e subdesenvolvidos.

O ponto para o qual chamamos atenção é o risco de se ter uma definição histórica do tempo que o contempla como um bloco coeso de sociedades que comungam do mesmo tipo de organização social e política e descartam aquelas outras que não se encaixam nesse modelo, como se por não compartilhar do mesmo modelo de desenvolvimento econômico, político e social, pudesse ser meramente descartado. O tempo do mundo, a nosso ver, "não pode ser a totalidade da história dos homens. Estamos às voltas com um 'tempo vivido nas dimensões do mundo'. E mais, um 'tempo excepcional' que governa segundo os lugares e as épocas, certos espaços e certas realidades" ${ }^{41}$.

Assim, conceber uma noção de 'tempo vivido nas dimensões do mundo' é o que nos permite afirmar e valorizar as caraterísticas do lugar que habitamos, que busca entender o processo histórico que ocorreram e transformaram os lugares, as pessoas, as formas sociais exatamente no que são hoje. Sem entender que somos herdeiros de um processo de acontecimentos de um mundo passado e que nos legou seus sucessos e fracassos e, ao qual precisamos dar seguimento, o conhecimento deste mundo e as possíveis soluções para o consertamos, torna-se uma tarefa extremamente difícil.

Dessa forma, percebendo a fragilidade de um discurso que de forma geral não leva em consideração as realidades de cada lugar, ou seja, seu processo histórico, que atribui a estes lugares arbitrariamente uma classificação no ranking do desenvolvimento mundial que não respeita suas particularidades, justificada em termos abstratos que servem apenas para distanciar os lugares em questão, percebemos que tal concepção de tempo, isto é, Tempo do Mundo, tem apenas a utilidade de ainda mais tornar intransponível a barreira social que afasta esses povos.

Buscando entender como tais questões afetam a realidade brasileira, faremos algumas análises de alguns fatores que acreditamos serem grandes responsáveis pela nossa situação política e social, sendo assim, seguindo na esteira das discussões anteriores, nos debruçaremos sobre os Direitos Humanos no Brasil. Para isso, no entanto, precisamos entender alguns aspectos que contribuíram para a nossa trajetória histórica até os dias atuais. Não iremos nos detalhar pormenorizadamente em cada evento histórico que compõe nossa

${ }^{41}$ ARANTES, 2014, p. 28. 
jovem nação, apenas apontaremos o que consideramos como sendo uma das principais causas de vermos hoje tantos ataques aos Direitos Humanos e a quem luta por eles.

Sendo assim, começamos por apontar uma causa que acreditamos ser uma das mais importantes a esse respeito: a falta de experiência que temos com nossa própria história. Vimos nos últimos meses, ou mesmo nos últimos anos como tem crescido argumentos de pessoas intolerantes que propagam práticas de violência como sendo uma resposta à própria violência, vemos e ouvimos discursos que começaram a se manifestar timidamente, mas que por conta de uma bipolarização muito radical no cenário político, encontrou o combustível que precisava pra disseminar seu ódio contra tudo aquilo de que discordam inclusive, louvar um tipo de regime político que usava de assassinatos, torturas, estupros, etc como práticas policiais corriqueiras, cotidianas, ou seja, tudo o que alguém pautado sob a política dos Direitos Humanos combate.

Assim, por todo o obscurantismo que envolve essa época da nossa história, pelo fato de não termos tido a chance de acertar as contas com esse passado, vemos tantas menções a ele, vemos pessoas que seriam as primeiras a sofrer as consequências negativas de tal forma de regime político exaltarem-no, a saber, pessoas em situação vulnerável, pobres, mulheres, etc. Estas questões dão-nos a necessidade de aprofundar um pouco mais nossa argumentação e, sendo assim, gostaríamos de tratar de um assunto um tanto controverso que já foi muito discutido e de diversas formas, mas que hoje se configura muito próximo de nossa realidade, o estado de exceção.

Durante as manifestações em oposição ao golpe em curso que atendia pelo nome de Impeachment, as falas de alguns líderes comunitários das favelas cariocas afirmavam que em suas comunidades não havia nenhum registro da passagem da democracia. Não havia nenhum aparato do governo que tivesse a função de formar um bom cidadão, de dar oportunidade de se formar bons cidadãos. Dentro daquela estrutura, não havia escola, posto de saúde, uma praça onde as famílias pudessem se reunir, um campinho de futebol de terra batida onde as crianças pudessem se divertir, nada disso, apenas uma única organização governamental estava presente, a polícia. Sabemos que essa realidade, infelizmente não é privilégio das favelas cariocas, as periferias brasileiras estão todas nessa mesma situação.

Segundo o filósofo alemão Walter Benjamin no texto de 1921, Sobre a Crítica do Poder como Violência, a polícia como uma instituição e manutenção do estado é um prolongamento desse poder, assim, "o que caracteriza o militarismo, que só chegou a ser o que é (...), é uma duplicidade na função da violência. O militarismo é a compulsão para o uso 
generalizado da violência como um meio para os fins do Estado ${ }^{42 " ~ o ~ q u e ~ n o s ~ p e r m i t e ~ c o n c l u i r ~}$ que um estado que depende do aparato policial para manter a ordem, é um estado que faliu.

A afirmação de que os fins do poder policial seriam sempre idênticos aos do direito restante ou pelo menos ligados a eles, é falsa. $\mathrm{Na}$ verdade o "direito" da polícia é o ponto em que o estado - ou por impotência ou devido às inter-relações imanentes a qualquer ordem judiciária - não pode mais garantir, através da ordem jurídica, seus fins empíricos, que deseja atingir a qualquer preço ${ }^{43}$.

A ser assim, qualquer ação da polícia torna-se uma ação do estado. E se por conta das ações da polícia, com a determinação do estado de se manter a ordem, arbitrariedades são cometidas, abusos são denunciados, a quem se deve recorrer? Se conforme o relato do líder comunitário, o único registro da atuação do Estado dentro das periferias brasileiras é através da repressão, se uma parte grande e muito importante da população brasileira não conhece a democracia, é possível falar em democracia no Estado brasileiro?

Se é a força policial o que tem mantido uma boa parte de nossa população em "ordem" e, a um preço muito alto para essa parte da população, é necessário ressaltar, então que é perfeitamente possível supor que vivemos sob o estado de exceção. Aliás, segundo Benjamin, não apenas vivemos em um estado de exceção, mas "o estado de exceção em que vivemos é a regra" ${ }^{44}$. O que desde as jornadas de junho e a impressionante mobilização policial para sufocá-la já se descortinava diante de nós, mas que só ultimamente principalmente no pós impeachment vimos em seu estado latente, com o crescimento do discurso fascista.

Então, se estivermos certos em nossa linha de raciocínio, se vivemos em um estado de exceção, se ele é regra, como fica os Direitos Humanos no meio disso tudo? Num estado de exceção, os Direitos Humanos se configura quase como um artigo de luxo. Nesse estado tem-se uma relação com a vida humana muito peculiar. Outro filósofo, agora o italiano, Giorgio Agamben criou um conceito que designa bem a relação que tem o estado de exceção com aquelas pessoas que considera como não-importantes, como descartáveis, o Homo sacer. Segundo a descrição deste conceito, "existem vidas humanas que perdem a tal ponto a qualidade de bem jurídico, que a sua continuidade, tanto para o portador da vida como para a sociedade, perdeu permanentemente todo o valor" ${ }^{45}$. Ele ainda acrescenta,

\footnotetext{
${ }^{42}$ BENJAMIN, Walter; Sobre a crítica do poder como violência; Ed. Autêntica; Belo Horizonte, 2012.

${ }^{43}$ Idem, ibidem.

${ }^{44}$ Tese VII, das Teses sobre o Conceito de História, 1940.

${ }^{45}$ AGAMBEN, 2010, p. 133.
} 
Toda a sociedade fixa este limite, toda a sociedade - mesmo as mais modernas - decide quais sejam seus "homo sacer". É possível, aliás, que este limite, do qual depende a politização e a exception da vida natural da ordem jurídico estatal não tenha feito mais do que alargarse na história do Ocidente e passe hoje - no novo horizonte biopolítico dos estados de soberania nacional - necessariamente ao interior de toda a vida humana e de todo o cidadão. A vida nua não está mais confinada a um lugar particular ou em uma categoria definida, mas habita o corpo biológico de cada ser vivente ${ }^{46}$.

Onde mais se encontrariam nossos "homo sacer"? As pacificações nas favelas cariocas é um ótimo exemplo para demonstrarmos a figura do Homo sacer. Como esquecer Amarildo? E de tantos outros que tiveram o mesmo destino que ele? As pacificações foram pensadas para formar um cinturão de segurança para os grandes eventos que o Rio iria sediar, a saber, Copa do mundo e Olimpíadas. Tornou-se necessário dar uma sensação de controle daquelas áreas, precisava-se garantir a segurança das milhares de pessoas que circulariam pelo Rio durante os eventos. Era mais uma vez o Estado atuando nas favelas de forma repressora para garantir o mínimo dessa segurança. O que importa se no meio do caminho, alguns corpos fiquem no chão?

Durante essa fase, destacamos uma fala da advogada e defensora dos Direitos Humanos, Gabriela Azevedo sobre a pacificação. De acordo com ela essa nova ordenação das favelas cariocas, é uma territorialização desse espaço, ou seja, é colocar de uma vez esse espaço sob a tutela repressora do estado. Assim, ela afirma que esse território "no qual se pode suspender o ordenamento, invisibilizar, incluir, excluir e matar (lato sensu) de várias formas ao sabor da vontade pública" ${ }^{47}$, se configura exatamente como disse os líderes comunitários que citamos anteriormente, como um espaço de exceção.

Assim, para voltarmos ao tema da falta de experiência do povo brasileiro com sua própria história, remontamos ao período da ditatura militar, momento de nossa história recente em que a exceção podia-se ver mais claramente. Somos os únicos no continente sulamericano a não fazer uma varredura nos documentos oficiais desse período, a não permitir que a verdade sobre os atos de terror cometidos naquela época sejam divulgados, a não punir ninguém pelo crime de tortura, o que, aliás, é um dos artigos que trata a Declaração Universal dos Direitos Humanos, redigida pela ONU em 1948. Por não termos a oportunidade de conhecer nossa própria história em seus detalhes mais sombrios, é que hoje é possível vermos a retomada do discurso fascista, louvando o período do regime militar. É claro que se sente

\footnotetext{
${ }^{46}$ AGAMBEN, 2010, p. 135.

${ }^{47}$ Citado In ARANTES, Paulo. O novo tempo do mundo, 2014, p. 362.
} 
também em outros lugares do mundo esse bafejar do fascismo, não se trata de uma exclusividade brasileira, mas o que diferencia o nosso caso é o fato de que discursos de ódio, de intolerância estão sendo realizados em espaços em que a simples menção desses discursos deveria ser punida, o que dizer então de estimulada?

\section{Conclusão}

Dada a inserção dos direitos humanos na nossa Constituição e sua importância na garantia de uma vida digna, que garanta condições básicas de existência como nutrição e saúde, que promova o desenvolvimento e a autonomia dos indivíduos independente de sua condição social, é preciso repensar sua inserção real na sociedade. Para tanto, a interpretação da realidade que seja construída a partir dela e não em negação da mesma é necessária. É preciso desvelar as estruturas teóricas e práticas que sustentam a inviabilização da promoção dos direitos humanos.

A causa dos Direitos humanos é algo muito complexo que se abre em diversas nuances. Neste artigo buscamos expô-las com a intenção de tentar identificar sua atuação em nosso território e como sua falta pode gerar problemas sociais muito graves e com consequências que se estendem a longo prazo. Os conceitos aqui trabalhados de capital simbólico, tempo do mundo, homo sacer, etc, foram pensados de forma a lançar luz sobre esta questão. A nossa realidade social é claro, ultrapassa tudo o que fora aqui desenvolvido, mas acreditamos que contribuímos um pouco para amplificar essa questão.

Dessa forma, sabemos que o que estaria por trás dos que negam ou limitam os direitos humanos, e sabemos o que reforça a importância da luta pela igualdade. O que então pode ser feito para reforçar os direitos humanos, além da luta para que eles sejam respeitados, como se pode proporcionar a igualdade e a liberdade em nosso país? Pode-se, em defesa dos direitos humanos, aumentar, democratizar o acesso ao capital cultural. Isto, pois, uma das formas mais basilares de garantir que esses direitos tenham uma face concreta é auxiliar o desenvolvimento da igualdade e promover a liberdade dos indivíduos.

A questão da formação de nossa população é de extrema importância para entendermos como uma parcela significativa desta pode hoje encontrar-se em situação tão vulnerável e como a reparação a um passado de grande injustiça sofrida por seus antepassados pode ser uma das maneiras de superar essa situação de vulnerabilidade em que estão imersos.

Entendemos que nossas questões são muito complexas, nosso passado de abandono a população é algo que ainda nos cobra uma capitulação. Os negros que em sua maioria se 
encontram nas periferias das grandes cidades, que outrora foram largados a própria sorte depois de séculos de escravidão, e ainda se encontram da mesma forma, entregues à própria sorte; os índios que foram dizimados pelos colonizadores, e ainda lutam para manter o mínimo de que precisam para não serem extintos de uma vez, como desejam os grandes latifundiários e pecuaristas do país; os trabalhadores rurais que sonham com uma demarcação de terras improdutivas para terem o direito de viver daquilo que plantam e criam; etc. a lista de excluídos não é pequena, tampouco sua reivindicação.

Precisamos nos familiarizar com nossa própria história, precisamos viver nas dimensões de nosso próprio mundo para a partir de cada nuance revelada dessa história, cada pormenor do qual não tínhamos a mais remota ideia, nos concebermos como brasileiros e poder realizar a potencialidade que tanto já foi exaltada de nosso povo e de nossa dimensão, para sermos o que nos pretendermos ser, um lugar mais justo e orgulhoso de sua própria história, de seu povo.

Enfim, a discussão sobre o papel dos Direitos Humanos dentro de uma sociedade desigual, injusta como a nossa é infinita, apenas desejamos muito que avancemos na luta pela garantia dos Direitos Humanos, principalmente para aqueles que nunca foram sequer reconhecidos assim, como humanos.

\section{REFERÊNCIAS}

AGAMBEN, Giorgio. Homo Sacer: O poder soberano e a vida nua I. Tradução de Henrique Burigo. Belo Horizonte: Editora UFMG, 2012.

ARANTES, Paulo. O novo tempo do mundo (Estado de sítio): $\mathbf{E}$ outros estudos sobre a era da emergência. São Paulo: Editora Boitempo, 2014.

ARBEX, Daniela. Holocausto Brasileiro - Vida, Genocídio e 60 Mil Mortes No Maior Hospício do Brasil, Geração: São Paulo, 2013.

BENJAMIN, Walter. Sobre o poder como violência. Org. BARRENTO, João. Walter Benjamin: O anjo da História. $2^{a}$ edição. Ed. Autêntica: Belo Horizonte, 2012. Teses Sobre Conceito de História. Org. BARRENTO, João. Walter Benjamin: O anjo da História. $2^{\text {a }}$ edição. Ed. Autêntica: Belo Horizonte, 2012.

BRASIL. Constituição da República Federativa do Brasil. Brasília, DF: Senado Federal: Centro Gráfico, 1988.

SOUZA, Jessé. A tolice da inteligência brasileira: ou como o país se deixa manipular pela elite. São Paulo: LeYa, 2015.

Recebido: agosto/20018

Aprovado: outubro/2018 